\title{
Calculating Changes in Worklife Expectancies and Lost Earnings in Personal Injury Cases
}

\author{
Michael Nieswiadomy \\ Eugene Silberberg
}

\begin{abstract}
This paper utilizes the Bureau of Labor Statistics (BLS) new worklife tables' information on workforce participation probabilities to estimate the effect of an injury on a worker's life expectancy, worklife expectancy and discounted expected income. After a medical opinion has been obtained concerning the effect of an injury on a worker's probabilities of living and remaining active, the BLS's probability figures can be adjusted and incorporated into a Markov process to estimate the impact of the injury. It is shown that Alter and Becker's technique can be adapted to estimate the present value of the lost expected income.
\end{abstract}

\section{Introduction}

The standard procedure in the projection of economic losses in personal injury (PI) cases involves projecting one or more base incomes (e.g., the "before" and "after" earning capacities) throughout the remainder of the plaintiff's expected working life. This is most commonly done with the use of various tables of expected worklife, for example, those published by the Bureau of Labor Statistics (BLS). Recently, the BLS published two updated versions of its worklife tables which provided more detailed information on labor force activity and inactivity than had been previously available $[6,7]$. The publication of this new version has prompted researchers to reevaluate the methodologies that had been used to calculate the present value of lost future earnings $[5,3]$. In particular, Alter and Becker $[1,2]$ have shown that the exact mathematical expectation of future earnings (the sum of expected yearly earnings over life) need not equal the sum of earnings over the expected worklife, a technique commonly employed by expert witnesses.

This paper implements the BLS data in a new context, the estimation of the economic loss associated with increased probability of injury. Section one of

Michael Nieswiadomy is Assistant Professor of Economics at the University of North Texas. Eugene Silberberg is Professor of Economics at the University of Washington. 
the paper briefly describes the nature of the problem in PI cases and examines the accompanying changes in life expectancy, worklife expectancy, and lost income. In section one, a modified version of the Alter and Becker method is used to calculate the present value of lost expected income. In section two, similar calculations are made for the case in which an injury increases both the probabilities of death and of workforce inactivity. Section three summarizes the paper's findings.

\section{Personal Injury and Increased Death Probability}

In many PI cases the problem becomes essentially a matter of carefully utilizing revised (ex post) probabilities. These situations occur when an injury does not immediately remove a person from the labor force, but in fact increases the probability that such an event will occur. For example, consider a plaintiff who has received a back injury, and who is at present displaying no symptoms, but about whom the medical opinion is that there is a significantly increased probability, say, two or three time the average for normal adults of that age, that a disabling injury will subsequently occur. Various courts have ruled recently that such increased probability of injury is a valid cause of action, even if it is established that the tort involved will not "more probably than not" cause a disabling injury to occur. In the Herskovits case, ${ }^{1}$ for example, failure to diagnose cancer in a timely manner reduced the plaintiff's probability of survival by 14 percent. The reduction of the probability of survival, even if by less than 50 percent, is actionable under the State of Washington's wrongful death statute. Since the nature of the problem is essentially probabilistic, use of the new worklife table's data on workforce activity and inactivity can facilitate the calculation of the effect of these changing probabilities on life and worklife expectancies and the associated economic losses.

Suppose that because of some injury, a medical conclusion is reached that a male plaintiff now has twice the normal probability of dying as he otherwise would have, and that this situation will persist for the rest of his life. What is the effect on expected life and worklife of such a conclusion? Since a formal derivation of life and worklife expectancies is provided elsewhere [6, p. 12], the details will not be presented here. Essentially, this article presents the same version of the Markov process as is used by the BLS and follows the same notation. For example, the life expectancy of a man at any given age is the number of "man-years" of life remaining ( $\left.{ }^{\circ} T_{x}^{1}\right)$ for the cohort alive at that age divided by the size of that cohort at the specified age $\left(1_{\mathrm{x}}\right)$. Worklife expectancy is defined as the remaining active man-years to be lived in the labor force beyond exact age $\mathrm{x}$, for all men regardless of labor force status at age $\mathrm{x}$, $\left(\mathrm{T}_{\mathrm{x}}^{\mathrm{a}}\right)$ divided by $1_{\mathrm{x}}$.

\footnotetext{
${ }^{1}$ See Herskovits v. Group Health, 99 Wn. 2nd 609, 664 p. 2 d 474.
} 


\section{Life Expectancy}

In the following examples the effects on the life and worklife expectancies of a hypothetical 35-year-old male will be analyzed. In Table 1, an initial cohort of 100,000 males is assumed. According to survival tables, the cohort will have 94,168 persons at age $35[6, p .17]$. This number is shown on the top of column 2. The remaining entries in this column show the number of survivors at each age up to 60 . In column 3 , the total number of man years of remaining life, ${ }^{-} T_{x}^{1}$, is shown, again for each age up to $60 .^{2}$ The life expectancy of average males is simply the ${ }^{\top} \mathrm{T}_{\mathrm{x}}^{1} / 1_{\mathrm{x}}$; these figures are given in column 4 for for various ages at five year intervals. Column 5 gives the size of the cohort that would survive under the assumption that the probability of death is doubled while column 6 gives the corresponding total number of man-years of remaining life when the probability of death is doubled. The implied life expectancies for these survival rates (beginning at age 35) are shown in column 7. The effect of a doubling of the death rate beginning at age 35 is to reduce the life expectancy of the 35 year old plaintiff by approximately eight years, from 37.61 years to 29.96. The remaining figures in column 7 must be interpreted with care. These figures assume normal survival rates to age 35 , and then double the normal death rates. The life expectancy of a 40 year old, given as 25.68 , is relevant only to these assumptions. If this plaintiff survives to age 40 , his life expectancy then will be 25.68 .

\section{Table 1}

Male Life Expectancies When the Probability of Death is Doubled

(1)

(2)

(3)

(4)

(5)

\begin{tabular}{c}
$\begin{array}{c}\text { Double } \\
\text { death } \\
\text { Probability" }\end{array}$ \\
\hline
\end{tabular}

Age Cohort

$35 \quad 94,168$

$40 \quad 92,955$

$45 \quad 91,147$

$50 \quad 88,334$

$55 \quad 84,016$

$60 \quad 77,826$
(3)

${ }^{\cdot} \mathbf{T}_{\mathbf{x}}^{\mathbf{1}}$
$3,541,203$
$3,073,220$
$2,612,653$
$2,163,444$
$1,731,902$
$1,326,318$

$\begin{gathered}\text { Life } \\ \text { Expectancy }\end{gathered}$
37.61
33.06
28.66
24.49
20.61
17.04

Probability"

Cohort

94,168

91,754

88,213

82,837

74,900

64,193
(6)
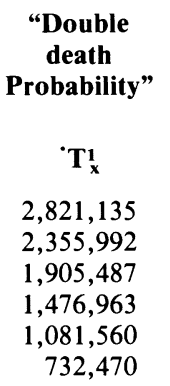

"Double death Probability"

Life Expectancy

29.96

25.68

21.60

17.83

14.44

11.41

\section{Worklife Expectancy}

In Table 2, worklife expectancies for normal males are calculated. In column 2 the normal worklife expectancy is shown. For a 35 year old male it is 24.72 years.

If the death rates are doubled after age 35 , the number of surviving active males will be reduced, and with it, ' $\mathrm{T}_{\mathrm{x}}^{\mathrm{a}}$. Column 3 lists these numbers of active

\footnotetext{
${ }^{2}$ These calculations are not exactly the same as the BLS's numbers [6, p. 52] due to slight differences in rounding and closure of the life table. These differences are quite small.
} 
males. Column 4 lists the corresponding number of inactive males. The sum of these two columns equals the surviving cohort. From the numbers of active males at each age, the corresponding man-years of active life following each age can be calculated. These results are displayed in column 5 . The worklife expectancies, shown in column 6 , of a population made up of such males (with twice the normal death rates) is found by dividing the active man-years by the surviving cohort, the sum of columns 3 and 4 . The worklife expectancy for a 35-year-old male with these characteristics is 22.57 years, down from the normal 24.72. It might seem surprising that the effects on life and worklife expectancies are as small as they are. The reason is that at this age, the death rate among normal males is not very high; thus, doubling it does not lead to high numbers of deaths in the population.

Table 2

Male Worklife Expectancies When Probability of Death is Doubled

(1)

Age
35
40
45
50
55
60

(2)

$\begin{gathered}\text { Normal } \\ \text { Worklife } \\ \text { Expectancy }\end{gathered}$
24.72
20.26
15.89
11.70
7.77
4.25

(3)

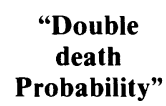

(4)

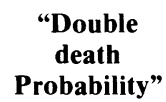

(5)

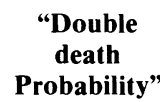

Tt

$$
\begin{array}{r}
2,125,044 \\
1,683,160 \\
1,258,133 \\
862,035 \\
513,260 \\
235,797
\end{array}
$$

(6)

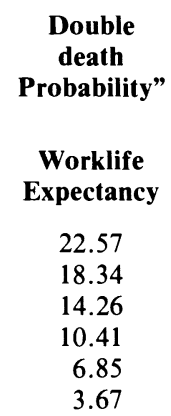

\section{The Economic Loss}

Since a determination of the expected worklife is not usually the final purpose in PI cases, a methodology is needed to utilize the BLS's new data to calculate the resulting economic loss. In this regard, Alter and Becker have presented a technique that can be adapted to analyze this problem. Since the authors are essentially only modifying Alter and Becker's [1] technique, the technique is not described here. Alter and Becker's notation is followed.

Let total annual earnings in year $\mathrm{n}\left\{\mathrm{y}_{\mathrm{o}} *(1+\mathrm{g})^{\mathrm{n}}\right\}$ be paid in two equal biannual payments. Also, let $\mathrm{M}$ represent the number of ages remaining after age $\mathrm{x}$ until the cohort is extinguished. Assume that persons who die or become inactive in a given year earn their income in the first half of the year and that an inactive person who becomes active has earnings in the second half of the year. The present value of the expected income for a person active at age $\mathrm{x}$ is:

$$
\begin{aligned}
& \text { PV of expected income }=\left(1 / \mathrm{A} 1_{\mathrm{x}}\right) \sum_{\mathrm{n}=0}^{M}\left\{\left(1-\mathrm{q}_{\mathrm{x}+\mathrm{n}}\right)\right. \\
& {\left[\left(0.5^{\mathrm{A}} 1_{\mathrm{x}+\mathrm{n}}\right)\left({ }^{\mathrm{A}} \mathrm{p}_{\mathrm{x}+\mathrm{n}}^{\mathrm{A}}\right) \mathrm{y}_{0}\left(((1+\mathrm{g}) /(1+\mathrm{r}))^{\mathrm{n}+.5}+((1+\mathrm{g}) /(1+\mathrm{r}))^{\mathrm{n}+1}\right)\right.} \\
& +\left(0.5^{\mathrm{A}} 1_{\mathrm{x}+\mathrm{n}}\right)\left({ }^{\mathrm{A}} \mathrm{p}_{\mathrm{x}+\mathrm{n}}^{\mathrm{I}}\right) \mathrm{y}_{0}((1+\mathrm{g}) /(1+\mathrm{r}))^{\mathrm{n}+.5}
\end{aligned}
$$




$$
\begin{aligned}
& \left.+\left(0.5^{\mathrm{I}} 1_{\mathrm{x}+\mathrm{n}}\right)\left({ }^{\mathrm{l}} \mathrm{p}_{\mathrm{x}+\mathrm{n}}^{\mathrm{A}}\right) \mathrm{y}_{0}((1+\mathrm{g}) /(1+\mathrm{r}))^{\mathrm{n}+1}\right] \\
& +\left(0.5^{\mathrm{A}} 1_{\mathrm{x}+\mathrm{n}}\right)\left(\mathrm{q}_{\mathrm{x}+\mathrm{n}}\right) \mathrm{y}_{0}((1+\mathrm{g}) /(1+\mathrm{r}))^{\mathrm{n}+.5}
\end{aligned}
$$

The intuitive meaning behind this formula is discussed in $[1,2]$.

An evaluation of the economic loss now can be made. Using a base income of $\$ 25,000$, a growth rate of 7.32 percent (the average growth rate in compensation for $1965-1985$ [8, p. 417]), and an interest rate of 8.08 percent (the average yield on 3-year T-bonds for the same period [8, p. 505]), the present value of expected income for an average active male, age 35, is $\$ 562,682$, in the normal case. When the probability of death is doubled, the present value of income falls to $\$ 517,150$. This represents a loss of $\$ 45,532$ or a 8.1 percent reduction in present value income.

\section{Increasing the Probability of Death and Inactivity}

It was seen that doubling the probability of death does not reduce present value income enormously. Now consider a modified assumption concerning the effect of a potentially disabling injury. Assume that a medical conclusion is reached that the plaintiff has twice the normal probability of dying, $\mathrm{q}^{*}=$ $2 q$, twice the probability of going from active to inactive, $A_{P} I^{*}=2^{A} P^{I}$, and one half the probability of going from inactive to active, $\mathrm{I}_{\mathrm{P}} \mathrm{A}^{*}=0.5^{1} \mathrm{PA} .{ }^{3}$ (This might be called "doubling the probability of death and inactivity.") The effect of this assumption on worklife expectancy is shown in Table 3.

Table 3

The Effect of an Injury on Male Worklife Expectancy When the Probability of Death and Inactivity is Doubled

(1)

Age
35
40
45
50
55
60

(2)

Active
89,448
80,485
72,531
61,950
47,675
26,897

(3)

$$
\begin{array}{r}
\text { Inactive } \\
4,720 \\
11,269 \\
15,682 \\
20,887 \\
27,225 \\
37,296
\end{array}
$$

(4)

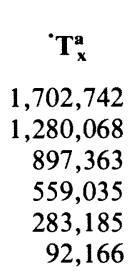

(5)

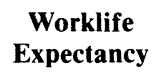

18.08

13.95

10.17

6.75

3.78

1.44

In column 2 the number of living and active members is shown. Column 3 shows the number of living and inactive males. In column 4 , the total number of active man-years remaining for each age is shown. The worklife expectancy, for a 35 year old man regardless of his labor force status, is given in column 5. It is calculated by dividing the total active man-years remaining by the total cohort (the sum of actives and inactives in columns 2 and 3 at each age). For a 35 -year-old it is 18.08 years, which is 6.64 years less than the normal 24.72

\footnotetext{
${ }^{3}$ Recall that ${ }^{\mathrm{PA}}$ and ${ }^{\mathrm{A}} \mathrm{PI}^{\mathrm{I}}$ are conditional probabilities in Becker and Alter [2]. Therefore, no double counting occurs. Also, other possible changes in $\mathrm{q}$, IPI, IPA, API and ${ }^{A} \mathrm{PA}^{\mathrm{A}}$ could be considered.
} 
years. This represents a 27 percent decrease in worklife expectancy. The remaining figures in column (5) must be interpreted in the same careful manner as the figures in column (7) of Table 1.

In Table 4 the effects on worklife expectancy of tripling, quadrupling and quintupling ${ }^{4}$ the probability of death and inactivity are shown to provide additional examples. ${ }^{5}$ The percent reductions in worklife expectancy for a 35-year-old male are 42, 52 and 60 percent, respectively.

\section{Table 4}

The Effect of an Injury on Male Worklife Expectancy

When the Probability of Death and Inactivity is

Tripled (3x), Quadrupled (4x), and Quintupled (5x)

(1)

Age at
Accident
Date

\section{5}

40

45

50

55

60
(2)

Normal
Worklife
Expectancy

24.72
20.26
15.89
11.70
7.77
4.25
(3)

$(\mathbf{3 x})$
$\begin{gathered}\text { Worklife } \\ \text { Expectancy }\end{gathered}$
14.28
11.22
8.34
5.77
3.44
1.32

(4)

(4x)

Worklife

Expectancy

11.76

9.21

6.81

4.69

2.76

0.97
Worklife

Expectancy

9.45

7.79

5.75

3.95

2.32

0.75

The economic loss involved is also significant. Doubling the probability of death and inactivity and assuming a 7.32 percent growth rate, an 8.08 percent discount rate, and a base income of $\$ 25,000$ in equation (1) result in a present value expected income figure of $\$ 422,597$ for an active 35 -year-old man. Thus, the economic loss is $\$ 140,085$. This represents a 24.9 percent reduction in present value income due to the injury. For the cases of tripling, quadrupling and quintupling the probability of death and inactivity, the percent reductions in present value income are 40,50 and 57 percent, respectively.

The above procedure is imprecise to the extent that the number of people leaving the labor force is not segregated as to cause. Unfortunately, the reasons for becoming inactive are unavailable in the data. If it is possible to estimate the number of retirees from separate data sources, the number of transitions to inactive status due to medical reasons may be estimated. This will require further research. However, the above numbers give a clear impression of the likely results for probabilities that are typical in personal injury litigation.

\footnotetext{
${ }^{4}$ Multiplying API by a factor of three, four, five, etc., will make ${ }^{A}{ }^{I}$ larger than one at later ages. It was set equal to one when this occurred. For example, when ${ }^{A} \mathrm{P}^{*}=5^{\mathrm{A}} \mathrm{PI}^{\mathrm{I}},{ }^{A} \mathrm{P}^{*}$ would be greater than one for ages greater than 65 . This is of minor significance since it occurs so late in life.

${ }^{5}$ The numbers in Table 4 must be interpreted differently than those in column (5), Table 3 . The worklife expectancies in Table 4 show the post injury remaining work years when the injury occurs at the age shown in the left hand column. These numbers can be compared with the usual worklife numbers, shown in column (2), Table 4, to determine the lost worklife years.
} 


\section{Summary}

This paper has presented a technique for evaluating the effect of an injury on a worker's life and worklife expectancies and expected income. It has been shown that the BLS's new worklife tables on workforce activity and inactivity provide especially useful information. Once a medical opinion has been provided, the appropriate probabilities can be adjusted to reestimate new life and worklife expectancies. It also has been shown that Alter and Becker's $[1,2]$ technique can be adapted to estimate the present value of the (pre- and post-injury) expected incomes.

\section{References}

1. Alter, George C. and William E. Becker, "Estimating Lost Future Earnings Using the New Worklife Tables," Monthly Labor Review, Vol. 108, No. 2 (February 1985), pp. 39-42.

2. Becker, William E., and George C. Alter, "The Probability of Life and Work Force Status in the Calculation of Expected Earnings," Journal of Risk and Insurance, forthcoming.

3. Boudreaux, Kenneth J., "A Further Adjustment Needed to Estimate Lost Earning Capacity," Monthly Labor Review, Vol. 106, No. 10 (October 1983), pp. 30-31.

4. Herskovits v. Group Health, 99 Wn. 2nd 609, 664 p. 2 d 474.

5. Nelson, David M., "The Use of Worklife Tables in Estimates of Lost Earning Capacity," Monthly Labor Review, Vol. 106, No. 4 (April 1983), pp. 30-31.

6. Smith, Shirley J., Tables of Working Life: The Increment-Decrement Model, Bulletin 2135, (Bureau of Labor Statistics, November 1982).

7. __ Worklife Estimates: Effects of Race and Education, Bulletin 2254, (Bureau of Labor Statistics, February 1986).

8. U. S. Department of Commerce, Bureau of Census, Statistical Abstract of the United States, 1985, 105th edition. 